\title{
Anxiety among the parents of pediatric patients receiving IVIG therapy during the Covid-19 pandemic
}

\author{
Özge Yılmaz Topal ${ }^{1 \oplus}$, Ayşe Metin $^{1 \oplus}$, Esra Çöp $^{2 \oplus}$, Gülser Şenses Dinç ${ }^{2 \oplus}$, \\ Özden Şükran Üneri ${ }^{3 \oplus}$
}

Divisions of ${ }^{1}$ Pediatrics Allergy and Immunology and ${ }^{2}$ Child and Adolescent Psychiatry University of Health Sciences, Ankara City Hospital, Ankara; ${ }^{3}$ Department of Psychology, İstanbul Gelişim University Faculty of Economics, Administrative and Social Sciences, İstanbul, Turkey.

\begin{abstract}
Background. Symptomatic COVID-19 cases in children occur mostly in those with primary immunodeficiency (PID), chronic lung diseases, and heart disease. Guidelines recommend that patients with PID continue to use their regular medication during the pandemic.

Objectives. This study aimed to evaluate anxiety related to COVID-19 in the parents of patients receiving intravenous immunoglobulin (IVIG) treatment in our hospital and to evaluate the effect of their anxiety on the continuity of treatment.

Methods. The parents of the patients who underwent IVIG therapy in our clinic during the pandemic (between May 15, 2020 and July 1, 2020) were included in our study.

Results. Twenty-seven patients with PID whose IVIG therapy was initiated before the pandemic and 29 nonPID control subjects were included in the study. All patients received IVIG treatment in our clinic continued treatment during the pandemic at the same dose intervals. Parents in the IVIG group had significantly higher state $(p=0.003)$ and trait $(p=0.003)$ anxiety scores compared to control parents. IVIG group showed statistically significant higher scores in Beck depression inventory, than the control group $(\mathrm{p}=0.002)$.

Conclusions. The parents of PID patients who needed to come to the hospital for IVIG therapy had higher anxiety levels than the parents of similar aged children who presented to our clinic for different complaints between the same dates. Despite their concerns, the parents of all patients under IVIG therapy maintained treatment continuity at the recommended treatment intervals. None of our immunodeficient patients who presented for treatment during the pandemic contracted COVID-19 infection during our study.
\end{abstract}

Key words: intravenous immunoglobulin treatment, anxiety, COVID-19, pandemic.

Primary immunodeficiencies (PIDs) are a congenital and heterogeneous group of disorders that can affect one or more systems. More than half of patients with PID have impaired antibody production. Affected individuals are more likely to have more severe and frequent infectious disease such as upper and lower respiratory tract infections, sinusitis, and opportunistic microorganism infections.

$凶$ Özge Yilmaz Topal

ozgeyilmaztopal@gmail.com

Received 27th January 2021, revised 3rd March 2021, 4th April 2021, accepted 9 April 2021.
Patients with predominant antibody deficiency need immunoglobulin therapy to reduce the risk of infection. ${ }^{1-3}$

Coronavirus disease 2019 (COVID-19, caused by the novel coronavirus SARS-CoV-2) has a spectrum ranging from asymptomatic to fatal infection disease. Among children, symptomatic COVID-19 cases have occurred mostly in those who have PID, chronic lung diseases, and heart disease. ${ }^{4}$ The European Academy of Allergy and Clinical Immunology (EAACI) recommends that patients with PID continue using their regular medication to avoid 
clinical exacerbations, underlying diseases, and complications, including autoimmune or other symptoms. ${ }^{5}$

Yuan et al. ${ }^{6}$ reported that the anxiety levels of parents of pediatric patients hospitalized during the COVID-19 pandemic were higher than in the non-epidemic period. Being in the hospital can increase the anxiety of patients and their parents due to the risk of nosocomial coronavirus transmission. ${ }^{6}$ Our study aimed to evaluate the anxiety that may occur due to COVID-19 in the parents of our patients who received intravenous immunoglobulin (IVIG) treatment in our hospital and to evaluate the effect of this anxiety on the continuity of treatment.

\section{Material and Methods}

The parents of patients who underwent IVIG therapy in our pediatric allergy and immunology clinic during the pandemic between May 15, 2020 and July 1, 2020 were included in our study. The control group included patients who had allergic rhinitis and no active symptoms and presented to the outpatient clinic for routine follow-up. The patients' age, sex, type of PID, follow-up times, and age at initiation of IVIG therapy were recorded in a standard form. In addition, any history of COVID-19 infection in the patients, their relatives, and the medical staff working in our clinic were recorded.

The parents' age and gender were recorded upon presentation to our clinic and they completed a questionnaire asking their opinions about coronavirus transmission. The contents of the questionnaire forms for the parents of patients receiving IVIG are given in Table I.

The study was approved by the institutional ethics committee of Ankara City Hospital (No: E1-20-648/ Date:2020) and the study protocol was approved by the Turkish Ministry of Health. Written informed consent was obtained from the parents or legal guardians of the patients.

\section{COVID-19 precautions in our center}

After the pandemic started, the body temperature of all patients and their parents were measured at the entrance of our hospital. They were also asked about any history of travel abroad, COVID-19 symptoms such as fever and cough, and contact with patients with known COVID-19 infection. Furthermore, everyone entering the hospital was required to wear a mask and observe social distancing rules.

Patients with fever and history suggesting possible COVID-19 infection were evaluated in separate pandemic outpatient clinics.

\section{Management of IVIG therapy}

Patients who had no symptoms of COVID-19 and no history of risky contact when they presented for treatment were admitted to the infusion room to receive IVIG therapy. Patients received IVIG therapy every 3 to 4 weeks. Dosage was 300 to $800 \mathrm{mg} / \mathrm{kg}$ at an infusion rate of 0.01 to $0.08 \mathrm{ml} / \mathrm{kg} / \mathrm{min}$, as tolerated by the patient. ${ }^{2,7,8}$

IVIG therapy was performed in a dedicated room separate from other patients. Social distance was observed and the number of people in the clinic was reduced by scheduling a certain number of patients for treatment per day and staggering appointments. Patients, their parents, and all health workers wore surgical masks during all procedures. The patients and their parents spent at least 4 hours in this room.

\section{Assessment of parental anxiety levels}

The State-Trait Anxiety Inventory (STAI) was used to assess the current and general anxiety levels of the patients' parents. The test-retest reliability coefficients in the initial development ranged from 0.31 to 0.86 with intervals ranging from 1 hour to 104 days. $^{9}$ The validity and reliability study of the Turkish version was performed by Oner and Le Compte. ${ }^{10}$ The state anxiety subscale consists of 20 items regarding 
Table I. The questionnaire form for the parents of patients receiving IVIG therapy.

\author{
Q1: Your age: \\ Q2: Gender: \\ $\square$ Female \\ $\square$ Male \\ Q3: Level of education \\ $\square$ Primary school \\ $\square$ Secondary school \\ $\square$ University \\ Q4: Place of residence \\ $\square$ In Ankara \\ $\square$ Outside of Ankara
}

Q5: How many years has your child been followed with a diagnosis of immunodeficiency?

Q6: What are the treatments your child is receiving due to immunodeficiency?

Q7: How long has your child been receiving IVIG treatment?

Q15: What do you think the likelihood is of you contracting COVID-19?

Q16: What do you think the likelihood is of your relatives contracting COVID-19?

Q17: What do you think the likelihood is of your child contracting COVID-19?

Q18: To what extent does the likelihood of contracting COVID-19 increase when you come to hospital for your child's immunotherapy?

Q19: What mode of transport are you coming to the hospital with?

Q20: To what extent does the likelihood of contracting COVID-19 increase during transit to the hospital for IVIG therapy?

Q21: What do you think the likelihood of your child contracting

COVID-19 from healthcare personnel who administerd the IVIG is?

Q22: What do you think the likelihood of your child contracting COVID-19 while waiting at the hospital during IVIG therapy (in the waiting and treatment rooms) is?

Q23: What do you think the likelihood of your child contracting COVID-19 from the doctor who examines your child before and after the IVIG therapy is?

Q24: What do you think the likelihood of your child contracting COVID-19 from the other patients who have come for IVIG therapy is?
Q8: How often does your child receive IVIG treatment? $\square$ Once every 3 weeks

$\square$ Once every 4 weeks

Q9: Does your child have any chronic and/or psychiatric diseases? If so, please state...

Q10: Do you have any chronic and/or psychiatric disease? If so, please state...

Q11: Have any of your relatives or friends developed symptoms of COVID-19?

$\square$ Yes

$\square$ No

If yes, please write who developed symptoms of corona virus infection?

Q12: Have you developed symptoms of COVID-19?

$\square$ Yes

$\square$ No

Q13: Have any of your relatives or friends had a confirmed COVID-19 infection?

$\square$ Yes

$\square$ No

If yes, please write whom:

Q14: Have you had a confirmed COVID-19 infection? $\square$ Yes

$\square$ No

$\begin{array}{ccccc}\square \text { Never } & \square 25 \% & \square 50 \% & \square 75 \% & \square \text { Absolutely } \\ \square \text { Never } & \square 25 \% & \square 50 \% & \square 75 \% & \square \text { Absolutely } \\ \square \text { Never } & \square 25 \% & \square 50 \% & \square 75 \% & \square \text { Absolutely } \\ \square \text { Never } & \square 25 \% & \square 50 \% & \square 75 \% & \square 100 \%\end{array}$

$\square$ Public transport $\square$ Private car

$\square$ Never $\square 25 \% \quad \square 50 \% \quad \square 75 \% \quad \square 100 \%$

$\square$ Never $\square 25 \% \quad \square 50 \% \quad \square 75 \% \quad \square 100 \%$

$\square$ Never $\square 25 \% \quad \square 50 \% \quad \square 75 \% \quad \square 100 \%$

$\square$ Never $\square 25 \% \quad \square 50 \% \quad \square 75 \% \quad \square 100 \%$

$\square$ Never $\square 25 \% \quad \square 50 \% \quad \square 75 \% \quad \square 100 \%$ 
the current state of anxiety. Feelings of subjective tension, nervousness, anxiety, and activation/ arousal "right now" are rated by selecting the response of "not at all", "somewhat", "moderately so", and "very much so". The trait anxiety subscale also consists of 20 items regarding anxiety tendencies independent of the current situation. The items evaluate the "general" frequency of emotions with options of "almost never", "sometimes", "often", and "almost always". 9,10 Higher scores indicate a higher level of anxiety.

The Beck Depression Inventory (BDI) was used to measure the presence and severity of various manifestations of depression. It is a 21-item selfreport instrument and total score ranges from 0 to $63 .{ }^{11}$ The validity and reliability study of the Turkish version was performed by Hisli et al. ${ }^{12}$

\section{Statistical Analyses}

Statistical analyses were performed using SPSS Statistics version 22.0 for Windows (IBM, Armonk, NY, USA) statistical software package. Continuous variables were expressed as mean and standard deviation for data with a normal distribution and as median and interquartile range (IQR) for non-normally distributed data. The chi-square test was used to compare nonparametric data; the Mann-Whitney $U$ test was used for comparisons among nonnormally distributed continuous variables and independent samples t-test for normally distributed continuous variables. A value of $\mathrm{p}<0.05$ was considered statistically significant

\section{Results}

Twenty-seven patients who received IVIG treatment due to PID before the pandemic and 29 control subjects were included in the study. The characteristics of the patients in study group are given in Table II.

The patients in the IVIG group had a median age of 12 (IQR: 8-15) years; median age in the control group was 11 (IQR: 6-14) years. The mean ages of the parents were $40.07 \pm 5.7$ (min-max: $31-51$ ) years in the IVIG group and $37.48 \pm 6.17$ (minmax: 22-48) years in the control group. There was no statistical difference between the groups in terms of the age of the patients $(p=0.300)$ or their parents $(\mathrm{p}=0.109)$.

All patients who were receiving IVIG treatment in our clinic continued treatment during the pandemic at the same dosing intervals. No patient exhibited an adverse reaction associated with IVIG therapy during the study period. In addition, none of the patients developed COVID-19 symptoms or had confirmed COVID-19 infection during treatment, nor

Table II. Demographic characteristics of patients receiving IVIG therapy.

\begin{tabular}{|c|c|}
\hline \multicolumn{2}{|l|}{ Gender n, \% } \\
\hline Male & $13(48.1)$ \\
\hline \multicolumn{2}{|l|}{ Age (years) } \\
\hline Mean (IQR) & $12(8-15)$ \\
\hline \multicolumn{2}{|l|}{ PID of the patients n, $\%$} \\
\hline CVID & $13(48.15)$ \\
\hline \multicolumn{2}{|l|}{ CID } \\
\hline ICF & $4(14.8)$ \\
\hline Ataxia-telangiectasia & $3(11.1)$ \\
\hline STAT1 deficiency & $1(3.7)$ \\
\hline IL-21R deficiency & $1(3.7)$ \\
\hline \multicolumn{2}{|l|}{ SCID } \\
\hline Jak-3 deficiency & $1(3.7)$ \\
\hline ALPS & $2(7.4)$ \\
\hline X-linked agammaglobulinemia & $1(3.7)$ \\
\hline $\begin{array}{l}\text { RAS-associated autoimmune } \\
\text { leukoproliferative disease }\end{array}$ & $1(3.7)$ \\
\hline \multicolumn{2}{|l|}{ Time interval of IVIG dosage } \\
\hline Once in 3 weeks & $3(11.1)$ \\
\hline Once in 4 weeks & $24(88.9)$ \\
\hline \multicolumn{2}{|l|}{ Duration of IVIG therapy } \\
\hline$<1$ years & $7(25.9)$ \\
\hline $1-2$ years & $4(14.8)$ \\
\hline 3-5 years & $3(11.1)$ \\
\hline$>5$ years & $13(48.1)$ \\
\hline
\end{tabular}

*PID: primary immune deficiency, CVID: common variable immune deficiency, CID: combined immunodeficiency, ICF: immunodeficiency with centromeric instability and facial anomalies, SCID: severe combined immune deficiency, ALPS: autoimmune lymphoproliferative syndrome, n: number, IQR: interquartile range 
did the examining physician, the nurse who administered IVIG therapy, or any of the other health workers.

According to the parents' responses on the COVID-19 questionnaire, 4 patients had relatives or friends diagnosed with COVID-19 in the control group. None of the parents in the IVIG group reported confirmed COVID-19 in their family or immediate social circle. In both groups, about half of the parents estimated their chance of contracting COVID-19 as about 25\% (IVIG group: 15/27, 55.6\%; control group: $14 / 29,48.3 \%)$. Similar proportions in each group believed their children also had a $25 \%$ chance of contracting COVID-19 (IVIG group: 15/27, 55.6\%; control group: 17/29, 58.6\%). The responses of the parents on the COVID-19 questionnaire are given in Tables III and IV. There was no difference between the two groups in the percentage of parents who believed their child's chance of contracting COVID-19 was $50 \%$ or higher $(\mathrm{p}=0.672)$.

When the percentage of the risk coming to the hospital was questioned among parents, 48.3\% $(14 / 29)$ of the parents in the control group answered as $50 \%$ and another $24.1 \%(7 / 29)$ of the parents replied as $25 \%$. In the IVIG group,
$40.7 \%(11 / 27)$ of the parents thought that coming to the hospital increased the risk of infection to $25 \%$, while $37 \%(10 / 27)$ of the parents thought it increased to $50 \%$. There was no statistical difference between the groups in the proportion of parents who stated that coming to the hospital increased the risk of infection to $25 \%$ or higher $(\mathrm{p}=0.44)$.

In the IVIG group, $40.7 \%(11 / 27)$ of the parents thought that there was almost no possibility of transmission from healthcare personnel other than physicians. Similarly, most parents in the same group thought that physicians did not increase the risk at all $(18 / 27 ; 66.7 \%)$. In the control group, a similar proportion of parents thought that there was almost no possibility of transmission from health personnel other than physicians $(12 / 29 ; 41.4 \%)$, while relatively fewer did not consider the physicians as increasing the risk of disease at all (14/29; $48.3 \%)$. There were no significant differences between the groups in the proportions of parents who believed that there was almost no possibility of transmission from health personnel other than physicians $(p=0.961)$, that there was no risk of transmission from physicians $(\mathrm{p}=0.165)$, and that $50 \%$ or more of the transmission risk was in the waiting and

Table III. Answers to questionnaire form for parents about parental COVID-19 history.

\begin{tabular}{|c|c|c|}
\hline & IVIG group n $(\%)$ & Control group $\mathrm{n}(\%)$ \\
\hline \multicolumn{3}{|c|}{$\begin{array}{l}\text { Have any of your relatives or friends developed symptoms of } \\
\text { COVID-19? }\end{array}$} \\
\hline Yes & $1(3.7)$ & $11(37.9)$ \\
\hline No & $26(96.3)$ & $18(62.1)$ \\
\hline \multicolumn{3}{|c|}{ Have you developed symptoms of COVID-19? } \\
\hline Yes & 0 & $2(6.9)$ \\
\hline No & $27(100)$ & $27(93.1)$ \\
\hline \multicolumn{3}{|c|}{$\begin{array}{l}\text { Have any of your relatives or friends had a confirmed COVID-19 } \\
\text { infection? }\end{array}$} \\
\hline Yes & 0 & $4(13.8)$ \\
\hline No & $27(100)$ & $25(86.2)$ \\
\hline \multicolumn{3}{|c|}{ Have you had a confirmed COVID-19 infection? } \\
\hline Yes & 0 & 0 \\
\hline No & $27(100)$ & $29(100)$ \\
\hline
\end{tabular}

n: number

Percentage values are calculated by columns 
Table IV. Answers to questionnaire form for parents about parental perceptions about COVID-19 risk.

\begin{tabular}{|c|c|c|c|c|c|}
\hline & $\begin{array}{l}\text { Never } \\
\mathrm{n}(\%)\end{array}$ & $\begin{array}{l}25 \% \\
\mathrm{n}(\%)\end{array}$ & $\begin{array}{l}50 \% \\
\mathrm{n}(\%)\end{array}$ & $\begin{array}{l}75 \% \\
\mathrm{n}(\%)\end{array}$ & $\begin{array}{l}\text { Absolutely } \\
\text { n (\%) }\end{array}$ \\
\hline \multicolumn{6}{|c|}{$\begin{array}{l}\text { What do you think the likelihood is of you } \\
\text { contracting COVID-19? }\end{array}$} \\
\hline IVIG group & $6(22.2)$ & $15(55.6)$ & 0 & $4(14.8)$ & $2(7.4)$ \\
\hline Control group & $4(13.8)$ & $14(48.3)$ & $7(24.1)$ & $4(13.8)$ & 0 \\
\hline \multicolumn{6}{|c|}{$\begin{array}{l}\text { What do you think the likelihood is of your } \\
\text { relatives contracting COVID-19? }\end{array}$} \\
\hline IVIG group & $5(18.5)$ & $13(48.1)$ & $6(22.2)$ & $3(11.1)$ & 0 \\
\hline Control group & $1(3.45)$ & $12(41.4)$ & $12(41.4)$ & $3(10.3)$ & $1(3.45)$ \\
\hline \multicolumn{6}{|c|}{$\begin{array}{l}\text { What do you think the likelihood is of your child } \\
\text { contracting COVID-19? }\end{array}$} \\
\hline IVIG group & $5(18.5)$ & $15(55.6)$ & $5(18.5)$ & $2(7.4)$ & 0 \\
\hline Control group & $3(10.3)$ & $17(58.6)$ & $8(27.6)$ & $1(3.45)$ & 0 \\
\hline \multicolumn{6}{|c|}{$\begin{array}{l}\text { To what extent does the likelihood of contracting } \\
\text { COVID-19 increase when you come to hospital? }\end{array}$} \\
\hline IVIG group & $2(7.4)$ & $11(40.7)$ & $10(37)$ & $2(7.4)$ & $2(7.4)$ \\
\hline Control group & $4(13.8)$ & $7(24.1)$ & $14(48.3)$ & $3(10.3)$ & $1(3.45)$ \\
\hline \multicolumn{6}{|c|}{$\begin{array}{l}\text { To what extent does the likelihood of contracting } \\
\text { COVID-19 increase during transit to the } \\
\text { hospital? }\end{array}$} \\
\hline IVIG group & $11(40.7)$ & $5(18.5)$ & $9(33.3)$ & $2(7.4)$ & 0 \\
\hline Control group & $16(55.2)$ & $6(20.7)$ & $4(13.8)$ & $3(10.3)$ & 0 \\
\hline \multicolumn{6}{|c|}{$\begin{array}{l}\text { What do you think the likelihood is of your } \\
\text { child contracting COVID-19 from the healthcare } \\
\text { personnel? }\end{array}$} \\
\hline IVIG group & $11(40.7)$ & $9(33.3)$ & $5(18.5)$ & $2(7.4)$ & 0 \\
\hline Control group & $12(41.4)$ & $8(27.6)$ & $7(24.1)$ & $2(6.9)$ & 0 \\
\hline \multicolumn{6}{|c|}{$\begin{array}{l}\text { What do you think the likelihood is of your } \\
\text { child contracting COVID-19 while waiting at the } \\
\text { hospital (in the waiting and treatment rooms)? }\end{array}$} \\
\hline IVIG group & $8(29.6)$ & $13(48.1)$ & $5(18.5)$ & $1(3.7)$ & 0 \\
\hline Control group & $4(13.8)$ & $12(41.4)$ & 11(37.9) & $1(3.45)$ & $1(3.45)$ \\
\hline \multicolumn{6}{|c|}{$\begin{array}{l}\text { What do you think the likelihood is of your child } \\
\text { contracting COVID-19 from the doctor who } \\
\text { examines your child? }\end{array}$} \\
\hline IVIG group & 18(66.7) & $8(29.6)$ & 0 & $1(3.7)$ & 0 \\
\hline Control group & $14(48.3)$ & $9(31)$ & $5(17.2)$ & $1(3.45)$ & 0 \\
\hline \multicolumn{6}{|c|}{$\begin{array}{l}\text { What do you think the likelihood is of your child } \\
\text { contracting COVID- } 19 \text { from the other patients } \\
\text { who have come to hospital? }\end{array}$} \\
\hline IVIG group & $5(18.5)$ & $15(55.6)$ & 0 & $7(25.9)$ & 0 \\
\hline Control group & $3(10.3)$ & $7(24.1)$ & $14(48.3)$ & $5(17.2)$ & 0 \\
\hline
\end{tabular}

n: number 
treatment rooms $(6 / 27$ patients [22.2\%] in the IVIG group; $13 / 29$ patients [44.8\%] in control group; $\mathrm{p}=0.074$ ).

Of the total 32 parents from both groups who stated that coming to the hospital increased their child's risk of COVID infection to $50 \%$ or higher, $18(56.25 \%)$ believed that $50 \%$ or more of the transmission risk was in the waiting and treatment rooms and $22(68.75 \%)$ thought the greatest risk was from other patients and their relatives.

When the STAI results were evaluated, the mean state anxiety score was 44.22 (SD: 11.18, minmax: 25-70) and the mean trait anxiety score was 44.37 (SD: 7.9, min-max: 33-63) in the IVIG group. In the control group, the mean state and trait anxiety scores were 36.07 (SD: 8.4, minmax: 24-53) and 37.9 (SD: 7.6, min-max: 26-53), respectively. Comparisons between the groups showed that the IVIG group had significantly higher scores for both state $(\mathrm{p}=0.003)$ and trait $(\mathrm{p}=0.003)$ anxiety (Table V).

The median BDI score was 10 (IQR: 7-13) in the IVIG group and 3 (IQR: 1-9.5) in the control group. IVIG group was found to have statistically significantly higher scores than the control group $(\mathrm{p}=0.002)$.

In the IVIG group, 15 patients were between 0 and 13 years old and 12 patients were 14 or older; in the control group, 18 patients were between 0 and 13 years old and 11 patients were 14 or older. There were no significant differences among parents in the IVIG and control groups when trait anxiety scores were compared according to the children's age group $(p>0.05)$. However, the parents of children over 14 years of age in the IVIG group had higher mean state anxiety score $(\mathrm{p}=0.023)$.

When IVIG and control group were evaluated together, the median STAI state anxiety score of the whole population was 41 . Using this as the cut-off value, there was a statistically significant difference between the IVIG and control groups in terms of the number of parents above this cutoff value. While the number of parents scoring 41 and above was $18(66.7 \%)$ in the IVIG group, it was $11(37.9 \%)$ in the control group $(p=0.032)$. Also in the IVIG group, the median age of the children of the parents with state anxiety scores of 41 and above were higher than those of parents with lower state anxiety scores (median age of the patients: $13.7 \& 8$ years; $p=0.004$ ).

\section{Discussion}

In this study of patients who needed to present to hospitals for regular IVIG therapy, it was observed that all patients whose treatment was initiated before the pandemic continued their treatment during the pandemic. The anxiety level of the parents of patients receiving

Table V. Demographic characteristics and depression and anxiety scores of parents.

\begin{tabular}{lccc}
\hline & $\begin{array}{c}\text { Parents in the IVIG group } \\
(\mathrm{n}=27)\end{array}$ & $\begin{array}{c}\text { Parents in the control group } \\
(\mathrm{n}=29)\end{array}$ & $\mathrm{P}$ \\
$\begin{array}{l}\text { Gender } \mathrm{n}, \% \\
\quad \text { Female }\end{array}$ & $20(74.1 \%)$ & $22(75.9 \%)$ & 0.87 \\
$\begin{array}{l}\text { Age (years) } \\
\quad \text { Mean }\end{array}$ & $40.07 \pm 5.7$ & $37.48 \pm 6.17$ & 0.109 \\
$\begin{array}{l}\text { STAI state anxiety score } \\
\quad \text { Mean }\end{array}$ & $44.22 \pm 11.18$ & $36.07 \pm 8.4$ & 0.003 \\
$\begin{array}{l}\text { STAI trait anxiety score } \\
\text { Mean }\end{array}$ & $44.37 \pm 7.9$ & $37.9 \pm 7.6$ & 0.003 \\
$\begin{array}{l}\text { Beck Depression Inventory score } \\
\quad \text { Median (IQR) }\end{array}$ & $10(7-13)$ & $3(1-9.5)$ & 0.002 \\
\hline
\end{tabular}

${ }^{*}$ : number, IQR: interquartile range 
IVIG therapy was found to be higher than in the control group. In both the control group and the IVIG group, most of the patients' parents believed that there was nearly no risk of transmission from physicians and other healthcare personnel. Due to preventive measures in the hospital and clinic, there was no transmission associated with the patients' hospital visits or treatment.

Currently available IVIG products do not contain specific antibodies against SARS-CoV-2, but they may include cross-reactive antibodies for SARS-CoV, Middle East respiratory syndrome coronavirus, or other human coronaviruses. Therefore, IVIG preparations could potentially provide some protection from COVID-19. ${ }^{13,14}$ The EAACI guideline, which addresses the management of immunodeficiencies during the SARS-CoV-2 pandemic, recommends that patients to continue the treatment they were receiving. ${ }^{5}$ The patients in our study had $100 \%$ treatment adherence and all patients were admitted to the hospital without delaying the time needed for treatment. We attribute this to having informed the patients and their families in detail about the disease and the fact that IVIG therapy would protect these patients against most infections. Despite high anxiety levels, all patients under IVIG treatment were fully compliant and continued at the same dose intervals as before the pandemic. This indicated that families consider protecting their children from illnesses more important than their own anxiety.

In our study, state anxiety scores assessed at hospital presentation were higher in the IVIG group than in the control group. There are no cut-off values or ranges to identify high anxiety levels for the Turkish version of the STAI. When we used the overall median state anxiety score as the cut-off value, we detected a statistical difference between the patient and control groups in terms of the proportions of parents above this threshold.

We also found that parents in the IVIG group had higher trait anxiety scores and higher median BDI scores compared to the control group. Although none of the parents exceeded the cut-off score of 17 for BDI, we believe this difference may be attributable to the BDI items that evaluate anxiety. It may also be related to awareness among parents in the IVIG group that their children's immunodeficiency put them at risk for many diseases and that COVID-19 infection could lead to more serious consequences in their children than in immunocompetent children.

The patients' IVIG infusions required them to spend several hours in the hospital. During this time, patients and their parents were advised to observe social distancing rules. In a study done in China, anxiety was reported to be more pronounced in the parents of children hospitalized during the epidemic. ${ }^{6}$ In both the IVIG and control group in our study, the majority of parents considered the likelihood of contracting COVID- 19 to be $25 \%$ at most and believed that coming to the hospital increased this risk to $25 \%$ or $50 \%$. Although the IVIG group having to spend a longer time in the hospital compared to the control group, there was no significant difference between the two groups in terms of the perceived increase in infection risk due to coming to the hospital and the perceived sources of potential transmission in the hospital.

The fact that parents did not think health workers, especially doctors, increased the risk of transmission is an important finding. These data can be interpreted as an indicator of the trust patients' families have in the protective measures taken by the health care professionals during the COVID-19 period. Although not evaluated in our study, possible factors contributing to this perception are media reports of health workers taking various measures to reduce the spread of the epidemic, reduce viral load, and reduce the burden on the health care system to ensure continuing accessibility to everyone, both in our country and worldwide. ${ }^{15}$ In addition, in our allergy and immunology clinic where the study was conducted, we continued regularly scheduled 
follow-up of all patients with severe and poorly controlled disease and explained to the families of patients who needed to come to the hospital that measures were taken to observe social distancing guidelines and create a suitable examination and treatment setting.

Our patients continued to receive treatment at the same doses and intervals in our hospital during the pandemic and none of them developed COVID-19 infection during the study period. In addition to the measures taken in our outpatient clinic, another contributing factor may be that patients requiring IVIG therapy underwent treatment in a room separate from other outpatients with social distancing and masks due to their status as a COVID risk group. All of these measures may explain the absence of nosocomial COVID-19 transmission among our patients during the study period. Our findings support the effectiveness of complying with mask and social distance guidelines and segregating risk groups in designated areas to reduce transmission among patients who must visit the hospital.

When the parents in the IVIG group were evaluated among themselves, it was determined that the parents of children aged 14 and over had higher state anxiety scores at presentation than the parents of children under 14 years old. Furthermore, in the IVIG group, the median age of the children of parents with state anxiety scores of 41 and above were higher than those of parents with lower state anxiety scores. Higher anxiety among the parents of adolescent children may be due to agerelated characteristics such as impulsivity and increased independent behavior.

The main limitation of this cross-sectional study is that the parents' pre-pandemic anxiety levels could not be evaluated. However, the difference observed between state and trait anxiety may indicate that their anxiety level increased with the pandemic. Another limitation of the study is that the anxiety levels of the pediatric patients in the IVIG group could be not determined. In fact, psychological distress in exposed children may lead to adverse events during the pandemic. ${ }^{16}$ The initial study plan included using ageappropriate anxiety scales to evaluate the patients as well, but the presence of comorbid mental retardation diagnosis in a substantial proportion of the patients in the IVIG group precluded this assessment. Another limiting factor was the different lengths of time spent in the hospital by the control and patient groups.

In conclusion, the treatment of pediatric patients with PID continued in our clinic during the COVID-19 pandemic. The parents of patients who needed to come to the hospital for this treatment were found to have higher anxiety levels than the parents of similar aged children who presented to our clinic for different complaints between the same dates. Despite their concerns, the parents of all patients under IVIG therapy ensured the necessary treatment continuity and maintained treatment adherence. None of our immunodeficient patients who required continued treatment during the pandemic contracted COVID-19 infection during our study, again highlighting the importance of measures such as masks, social distance, and the use of designated areas in limiting transmission.

\section{Ethical approval}

The study was approved by the institutional ethics committee of Ankara City Hospital (No: E1-20-648/ Date: 2020) and the study protocol was approved by the Turkish Ministry of Health.

\section{Author contribution}

The authors confirm contribution to the paper as follows: study conception and design: OYT, AM, OSU; data collection: OYT, AM; analysis and interpretation of results: OYT, AM, OSU, EC, GSD; draft manuscript preparation: OYT, AM, OSU, EC, GSD. All authors reviewed the results and approved the final version of the manuscript. 


\section{Source of funding}

There is no financial support.

\section{Conflict of interest}

None to declare.

\section{REFERENCES}

1. Seidel MG, Kindle G, Gathmann B, et al; ESID Registry Working Party and collaborators. The European Society for Immunodeficiencies (ESID) Registry Working Definitions for the Clinical Diagnosis of Inborn Errors of Immunity. J Allergy Clin Immunol Pract 2019; 7: 1763-1770.

2. Cunningham-Rundles C. Key aspects for successful immunoglobulin therapy of primary immunodeficiencies. Clin Exp Immunol 2011; 164(Suppl 2): 16-19.

3. Slatter MA, Gennery AR. Clinical immunology review series: an approach to the patient with recurrent infections in childhood. Clin Exp Immunol 2008; 152: 389-396.

4. Dong $\mathrm{Y}, \mathrm{Mo} \mathrm{X}, \mathrm{Hu} \mathrm{Y}$, et al. Epidemiology of COVID-19 among children in China. Pediatrics 2020; 145: e20200702.

5. Brough HA, Kalayci O, Sediva A, et al. Managing childhood allergies and immunodeficiencies during respiratory virus epidemics - The 2020 COVID-19 pandemic: a statement from the EAACI-section on pediatrics. Pediatr Allergy Immunol 2020; 31: 442448.

6. Yuan $\mathrm{R}, \mathrm{Xu} \mathrm{QH}, \mathrm{Xia} \mathrm{CC}$, et al. Psychological status of parents of hospitalized children during the COVID-19 epidemic in China. Psychiatry Res 2020; 288: 112953.

7. Bonilla FA, Khan DA, Ballas ZK, et al; Joint Task Force on Practice Parameters, representing the American Academy of Allergy, Asthma \& Immunology; the American College of Allergy, Asthma \& Immunology; and the Joint Council of Allergy, Asthma \& Immunology. Practice parameter for the diagnosis and management of primary immunodeficiency. J Allergy Clin Immunol 2015; 136: 1186-1205.e1-78.
8. Aghamohammadi A, Farhoudi A, Nikzad M, et al. Adverse reactions of prophylactic intravenous immunoglobulin infusions in Iranian patients with primary immunodeficiency. Ann Allergy Asthma Immunol 2004; 92: 60-64.

9. Julian LJ. Measures of anxiety: State-Trait Anxiety Inventory (STAI), Beck Anxiety Inventory (BAI), and Hospital Anxiety and Depression Scale-Anxiety (HADS-A). Arthritis Care Res (Hoboken) 2011; 63(Suppl 11): S467-S472.

10. Öner N, Le Compte WA. Durumluk-Sürekli Kayg1 Envanteri El Kitabı. İstanbul: Boğaziçi Üniversitesi Yayınları, 1983: 333.

11. Beck AT, Ward CH, Mendelson M, Mock J, Erbaugh J. An inventory for measuring depression. Arch Gen Psychiatry 1961; 4: 561-571.

12. Hisli N. Beck depresyon envanterinin üniversite öğrencileri için geçerliği, güvenirliği. Psikoloji Dergisi 1989; 7: 3-13.

13. Diez JM, Romero C, Gajardo R. Currently available intravenous immunoglobulin contains antibodies reacting against severe acute respiratory syndrome coronavirus 2 antigens. Immunotherapy 2020; 12: $571-576$

14. Gao X, Zhou H, Wu C, et al. Antibody against nucleocapsid protein predicts susceptibility to human coronavirus infection. J Infect 2015; 71: 599602.

15. Kissler SM, Tedijanto C, Goldstein E, Grad YH, Lipsitch M. Projecting the transmission dynamics of SARS-CoV-2 through the postpandemic period. Science 2020; 368: 860-868.

16. Jiao WY, Wang LN, Liu J, et al. Behavioral and emotional disorders in children during the Covid-19 epidemic. J Pediatr 2020; 221: 264-266.e1. 